\title{
Hygrothermal conditions in ventilated attics with different air change rates and ceiling constructions
}

\author{
Martin Morelli1, ${ }^{1,}$ Eva Møller ${ }^{2}$, and Thor Hansen $^{3}$ \\ ${ }^{1}$ Aalborg University, Department of the Built Environment, A.C. Meyers Vænge 15, 2450 Copenhagen, Denmark \\ ${ }^{2}$ Technical University of Denmark, DTU Civil Engineering, Brovej, Building 118, 2800 Kongens Lyngby, Denmark \\ ${ }^{3}$ Danish Technological Institute, Gregersensvej 1, 2630 Taastrup, Denmark
}

\begin{abstract}
A recently Danish study reported that no vapour barrier is needed in ceilings, if the attic is well ventilated and the ceiling towards the dwelling is airtight. Based on that study, new investigations were initiated with focus on the hygrothermal behaviour in ventilated attics with different air change rates. A test house with three sets of four different ceiling constructions - all airtight - was used in this study. The ventilation rate was reduced in two of the sets with approx. $35 \%$ and $50 \%$, respectively. Air change rates were measured with tracer gas. Furthermore, temperature and relative humidity was measured every hour. Measurements in similar ceilings with mineral wool or cellulose-based insulation material show that hygroscopic properties of the insulation have very limited effect on relative humidity. Furthermore, only at low ventilation rate the effect of a vapour barrier could be measured with minor impact. Based on the short-measured period the calculations of the risk of mould growth showed no risk. The results indicate that even when the ventilation is reduced by $50 \%$, the ventilated attic still performs well if the ceiling is highly airtight. However, the importance of vapour barriers becomes more important at lower air change rates.
\end{abstract}

\section{Introduction}

Recently, a study on the need for vapour barriers below ventilated attics was finished $[1,2]$. The study investigated when there is a need for vapour barrier depending on insulation thickness and type. The reason for that study was that there exists a common understanding that below $150 \mathrm{~mm}$ insulation no vapour barrier is needed [3], however, a vapour barrier must be installed towards the unheated attic if the total thickness of insulation exceeds $150 \mathrm{~mm}$. Despite this recommendation, manufactures of cellulose based insulation material have stated that due to the hygroscopic properties of cellulose, their product can handle more moisture compared to e.g. mineral wool, and no hygrothermal problem will occur at thicknesses above $150 \mathrm{~mm}$, even without vapour barrier. The outcome of that study $[1,2]$ was that if the ceiling is airtight and the ventilation follow normal Danish guidelines, there is no need for a vapour barrier neither when using mineral wool nor cellulose based insulation material. This has led to changes in the common understanding of whether to install a vapour barrier when renovating cold attics. The new recommendation is still to install a vapour barrier in both renovation projects and new buildings to ensure airtightness. Nevertheless, in renovation projects it can be difficult to ensure the tightness of the vapour barrier to trusses etc. Since the beginning of 2019, the guidelines [4] have been expanded to also include when a vapour barrier can be omitted. All the following conditions must be fulfilled:
- Airtightness and ventilation in the existing ceiling must be sufficient, which can be investigated by inspecting the attic for mould growth and dampness. If no signs are visible, the airtightness can be judged as sufficient.

- Airtightness and ventilation of the attic must not be reduced by the renovation.

This implies,

- Only parts of the roof that can be inspected can fulfil the conditions, i.e. cold attics, eaves voids and attics above collar beam.

- The airtightness must not be reduced e.g. by penetrating the ceiling from light installations or changing the construction (or surface).

- The installation of additional insulation must not reduce the ventilation openings.

The airtightness is a prerequisite for a wellfunctioning solution without vapour barrier, and as seen in the bullets many situations can contribute to reduced airtightness. The reason to focus on airtightness is that large amounts of moisture are transported by convection compared to diffusion.

The work presented in this paper is based on the fullscale test building presented in [1]. However, the present study investigates the influence on the moisture conditions in the attic when reducing the ventilation rate, i.e. reduction of approx. $35 \%$ and $50 \%$, compared to the recommendation given in [3], which are based on practical experience. The test house had six different

\footnotetext{
* Corresponding author: marmo@build.aau.dk
} 
MX.2: $400 \mathrm{~mm}$ mineral wool insulation, $13 \mathrm{~mm}$ gypsum board

MX.4: $400 \mathrm{~mm}$ cellulose-based insulation, $13 \mathrm{~mm}$ gypsum board

MX.5: $400 \mathrm{~mm}$ mineral wool insulation, vapour barrier, $13 \mathrm{~mm}$ gypsum board

MX.6: $400 \mathrm{~mm}$ cellulose-based insulation, vapour barrier, $13 \mathrm{~mm}$ gypsum board

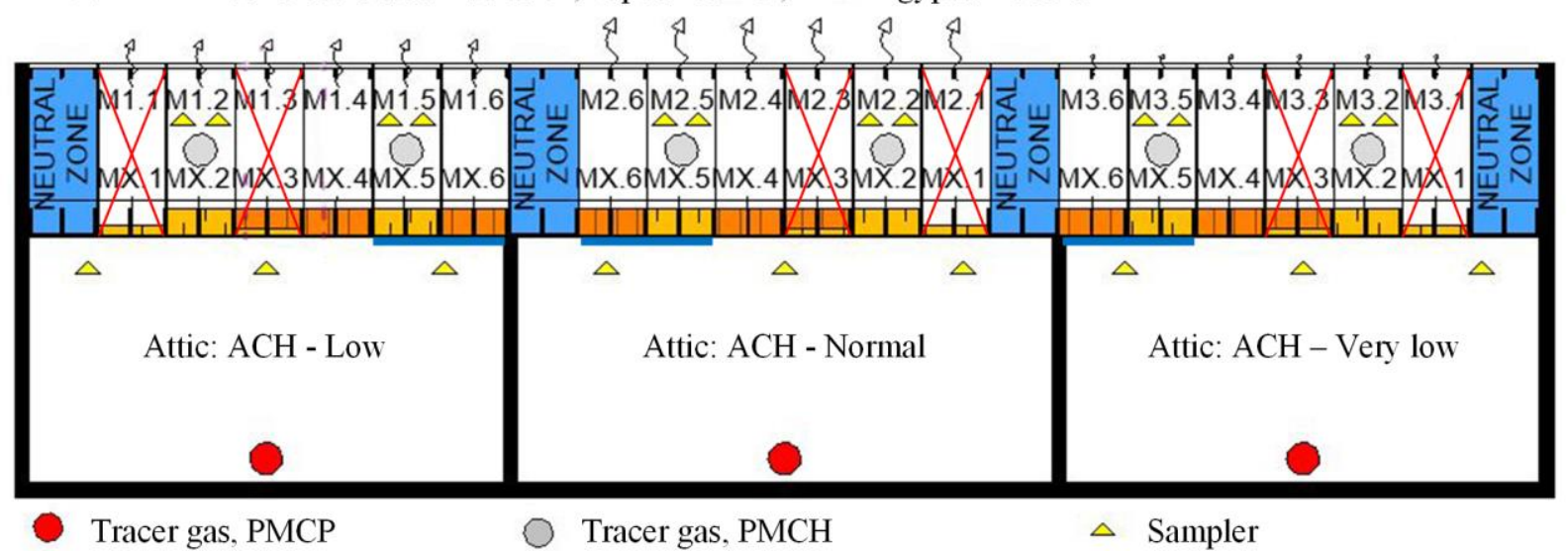

Fig. 1. Test house and ceiling construction. For example, MX.2 refers to either M1.2, M2.2 or M3.2 etc. Constructions marked with a red $\mathrm{X}$ are not considered in this paper.

ceiling constructions; however, this study only included four ceilings with $400 \mathrm{~mm}$ insulation, testing the influence of insulation type, effect of vapour barrier and ventilation rates. As the test house had three sets of the different ceiling constructions, it was possible to test three different ventilation rates in similar constructions and indoor condition at the same time, see Figure 1.

\section{Method}

In the test house, temperature and relative humidity in four attics with different ceiling construction were measured. Moreover, the ventilation rate was determined by tracer gas measurements. Finally, the risk of mould growth was calculated from the measured data.

\subsection{Test house}

The test house, located in Copenhagen, Denmark, consisted of three rooms with identical indoor climate that was adjusted to approx. humidity class 2 according to EN ISO 13788 [5] and $20^{\circ} \mathrm{C}$, see Figure 2.

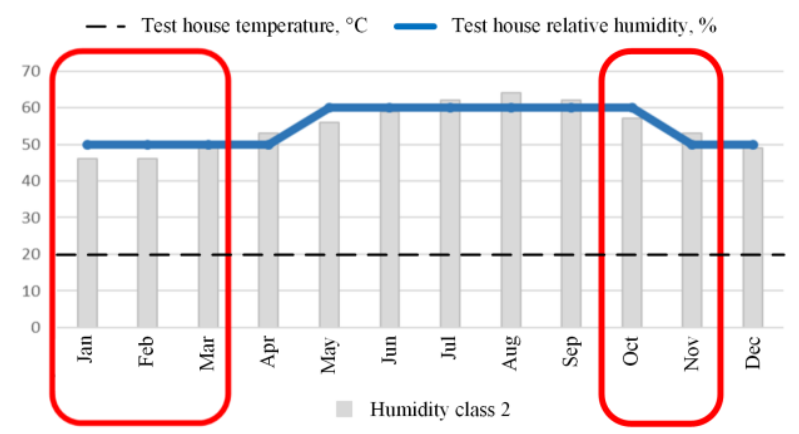

Fig. 2. Temperature and relative humidity in the test house; columns describe indoor relative humidity in humidity class 2 in a test reference year in Denmark. For simplicity, the relative humidity was set according to the blue solid line.
The building had facades to the north and south and a $30^{\circ}$ pitched roof ventilated between the light grey steel plates and diffusion-tight roof underlay consisting of a membrane, see Table 1.

Table 1. Material properties of ceiling construction.

\begin{tabular}{|l|c|c|c|}
\hline & $\begin{array}{c}\text { Thickness } \\
{[\mathrm{mm}]}\end{array}$ & $\begin{array}{c}\lambda \text {-value } \\
{[\mathrm{W} / \mathrm{mK}]}\end{array}$ & $\begin{array}{c}\mathrm{S}_{\mathrm{d}} \text {-value } \\
{[\mathrm{m}]}\end{array}$ \\
\hline $\begin{array}{l}\text { Gypsum } \\
\text { board }\end{array}$ & 12.5 & 0.2 & 0.1 \\
\hline $\begin{array}{l}\text { Vapour } \\
\text { barrier }\end{array}$ & 0.2 & - & 140 \\
\hline Mineral wool & 400 & 0.041 & 0.4 \\
\hline $\begin{array}{l}\text { Cellulose } \\
\text { based }\end{array}$ & 400 & 0.039 & $0.4-1.6$ \\
\hline Roof underlay & - & - & 160 \\
\hline
\end{tabular}

Four different ceiling constructions were built above each room, and in each attic section above one room, the ventilation openings were identical; however, the ventilation opening areas varied depending on the room, see Figure 1. The ventilation in the attics was reduced from the recommended ventilation area (100\%: $\mathrm{ACH}-$ Normal) by changing the opening areas at eaves and ridge to $66 \%(\mathrm{ACH}-$ Low) and $33 \%(\mathrm{ACH}-$ Very low) of the recommended ventilation area. The recommended ventilation area corresponds to an opening area at ridge of $100 \mathrm{~cm}^{2}\left(2 \times 50 \mathrm{~cm}^{2}\right)$ in each attic section. At eaves, the effective opening area was $15 \mathrm{x}$ $440 \mathrm{~mm} / \mathrm{m}$ corresponding to $132 \mathrm{~cm}^{2} / \mathrm{m}$.

Each ceiling construction used in this paper consisted of (from room to attic): gypsum boards, made airtight by sealing with vapour-barrier tape, possible vapour barrier and $400 \mathrm{~mm}$ insulation material. The insulation material was either mineral wool or cellulose-based material. For further description of the test house, see [1]. 
The diffusion-equivalent air layer thickness $\left(\mathrm{s}_{\mathrm{d}}\right)$ (water vapour diffusion resistance, $Z$ ) of the ceilings were:

- Ceilings with vapour barrier approx. $141 \mathrm{~m}$ (Zvalue: $742 \mathrm{GPa} \mathrm{m}^{2} \mathrm{~s} / \mathrm{kg}$ )

- Ceilings without vapour barrier approx. $1 \mathrm{~m}$ (Zvalue: $5 \mathrm{GPa} \mathrm{m}^{2} \mathrm{~s} / \mathrm{kg}$ ), see Table 1 .

Differences caused by differences in insulation material were insignificant and therefore disregarded.

\subsection{Temperature and RH measurements}

The measurements were conducted from January to November 2019. The results in this paper are reported from 20 January to 31 March 2019 (Part 1) and 1 October to 30 November 2019 (Part 2), as these periods are of interest regarding the moisture condition in attics. In each attic, four measuring points of temperature and relative humidity were installed, se Figure 3 . One measuring point was hanging from the trusses about 0.5 $\mathrm{m}$ below the ridge. The other three measuring points were on the trusses about $3 \mathrm{~cm}$ below the roof underlay; one in the ridge and one on approx. the middle of each roof surface. Differences between the measured values of the four sensors were small; therefore, the results are an average of these four measurements, with moving average for a period of 7 days.

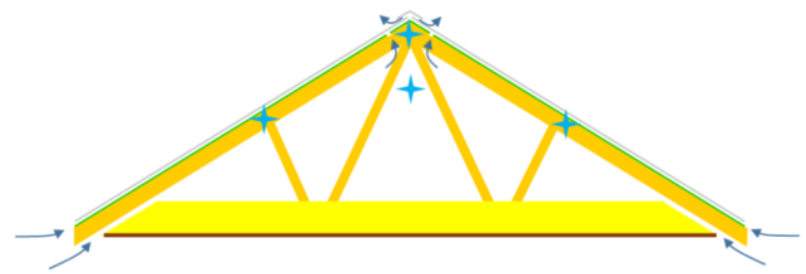

Fig. 3. Location of the four measuring point in attics.

To measure temperature and relative humidity, sensors of type HTemp-1Wire were used. The precision of the sensors was for temperature $\pm 1.0{ }^{\circ} \mathrm{C}$ in the range from $-10{ }^{\circ} \mathrm{C}$ to $+70{ }^{\circ} \mathrm{C}$ and for moisture $\pm 2.5 \% \mathrm{RH}$ in the range of $20-80 \% \mathrm{RH}$.

\subsection{Ventilation rate measurements}

To validate the reduced ventilation rate in the attic and infiltration from the rooms to attics, tracer gas measurements were conducted in the attics and rooms. Two different tracer gases were used, see Figure 1, that is $\mathrm{PMCH}$ - Perfluormethylcyclohexane (grey dot in attics), PMCP - Perfluormethylcyclopentane (red dot in rooms) and the samplers are shown as the yellow triangles. Attic MX.2 and MX.5 were used as both have $400 \mathrm{~mm}$ mineral wool insulation with and without vapour barrier.

The measurements were conducted from 18 January to 11 February 2019. In the attics, the tracer gas was released just above the insulation and the samplers were located with $0.5 \mathrm{~m}$ distance from the ridge ventilation opening. The volume of an attic was approx. $5.4 \mathrm{~m}^{3}$ and the rooms approx. $110 \mathrm{~m}^{3}$. The air change rates in the attics were calculated according to the method described in [6].

\subsection{Risk of mould growth}

Due to the lack of consecutively data collection, an initial validation of the risk of mould growth was performed. The chosen mould growth model was the MRD model (Mould Resistance Design) as described by $[7,8]$. The model only needs temperature and relative humidity plus a $\mathrm{D}_{\text {crit }}$ value, which describes the days, required for mould growth at $90 \% \mathrm{RH}$ and $20^{\circ} \mathrm{C}$. In this case, $\mathrm{D}_{\text {crit }}$ was set to 17 days corresponding to Norway spruce planed in a sawmill [8]. As threshold value a MRD index of 1 has been chosen; this corresponds to "Moderate but clear growth detected with microscopy" $[7,8]$.

\section{Results}

The tracer gas measurements in the individual attics showed a higher concentration of gas in attics with reduced opening areas. This clearly indicate a reduced air change rate in these attics, see Table 2 and Figure 4.

Furthermore; the investigation of the infiltration of tracer gas from the rooms to the attics showed larger gas concentration in the attics without a vapour barrier, see Figure 5.

Table 2. Average air changes in attics and reduction of ventilation in attics.

\begin{tabular}{|l|c|c|}
\hline & $\mathrm{ACH}_{\text {average }}\left[\mathrm{h}^{-1}\right]$ & Reduction [\%] \\
\hline $\mathrm{M} 2.2$ / M2.5 & 6.2 & 0.0 \\
\hline $\mathrm{M} 1.2$ / M1.5 & 4.0 & 35.1 \\
\hline $\mathrm{M} 3.2$ / M3.5 & 3.0 & 51.5 \\
\hline
\end{tabular}

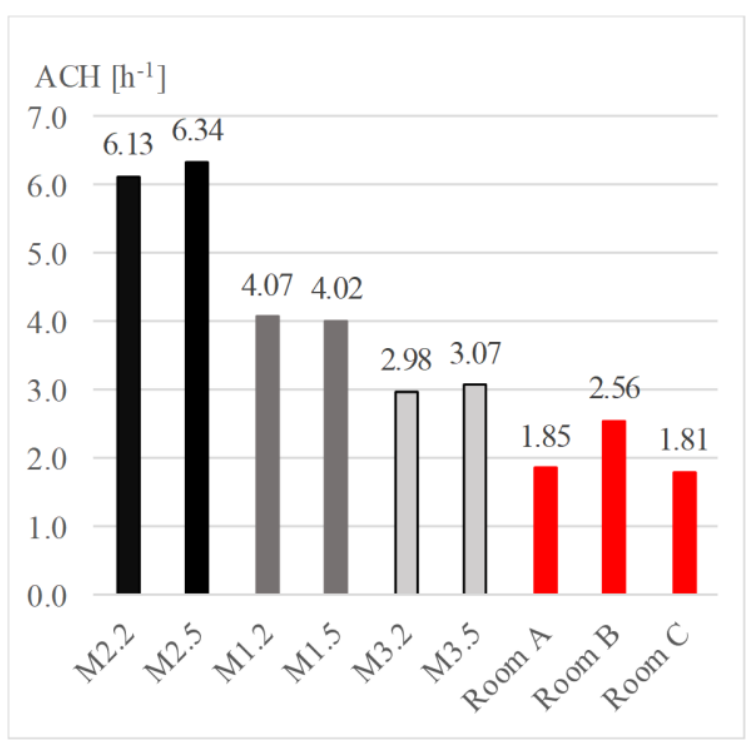

Fig. 4. Air change rates (ACH) in attics and rooms based on tracer gas measurements. Attics denoted MX.5 had vapour barriers and MX.2 had no vapour barrier. 


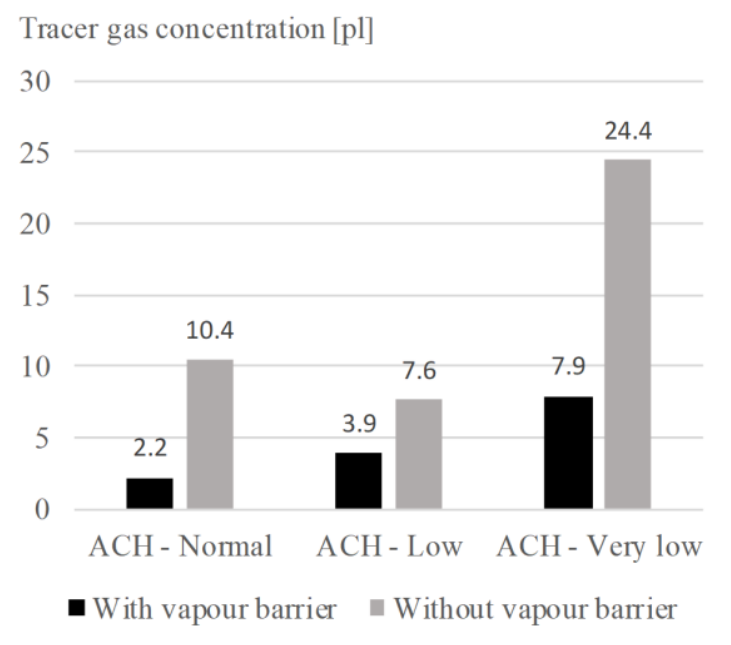

Fig 5. Concentration of tracer gas released in the room measured in attics with and without vapour barrier.

Figure 6 and 7 show the results of the temperature and relative humidity based on the average of four measurement points in the attics. Figure 6 shows the results in Part 1 of the measuring period (beginning of 2019). Figure 7 shows the results in Part 2 of the measuring period (end of 2019). The figures show that with reduced ventilation, the relative humidity increases slightly if there is no vapour barrier. The relative humidity increases slightly for all situation when the ventilation rate is reduced, especially seen for Part 1.

\section{Without VB}
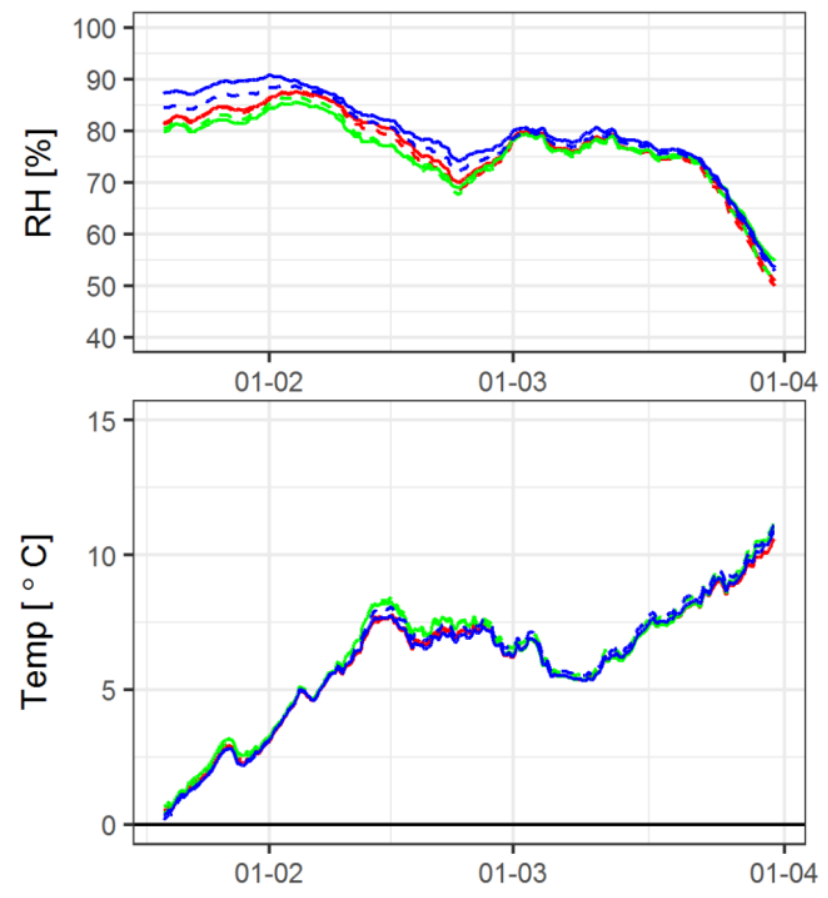

$\mathrm{ACH}$

\section{Discussion}

The measurements of the ventilation rate showed, that it was possible to reduce the ventilation rate by partly blocking the openings. The reduction was planned to be $33 \%$ and $66 \%$, respectively, however, it was measured with tracer gas to be $35 \%$ and $52 \%$ respectively.

The tracer gas measurements showed that the air exchange from the rooms to the attics was highly influenced by the ventilation rate in the respective attic and the presence of a vapour barrier. It was to be expected that also the concentration of the tracer gas from the room below would be reduced with higher ventilation rate in the attic. A tendency that is clear from Figure 5, although the concentration in the section without vapour barrier and little reduced ventilation (ACH - Low) is lower than the same section with normal ventilation (ACH - Normal). The most significant difference is how the vapour barrier changes the concentration; here it is clear that there is an effect of a vapour barrier, the reduction is between $48 \%$ and 80 $\%$. The highest reduction was where the ventilation rate was as recommended (ACH - Normal), again the relatively low tracer gas concentration in the section without vapour barrier and little reduced ventilation (ACH - Low) blurred the picture. The effect of ventilation was also higher for construction with vapour barrier than without, cf. Figure 5. This means that penetrated moisture from the indoor room is removed more sufficient with higher ventilation rate in the attic. Thereby, it must be expected that if the indoor air has a

\section{With VB}
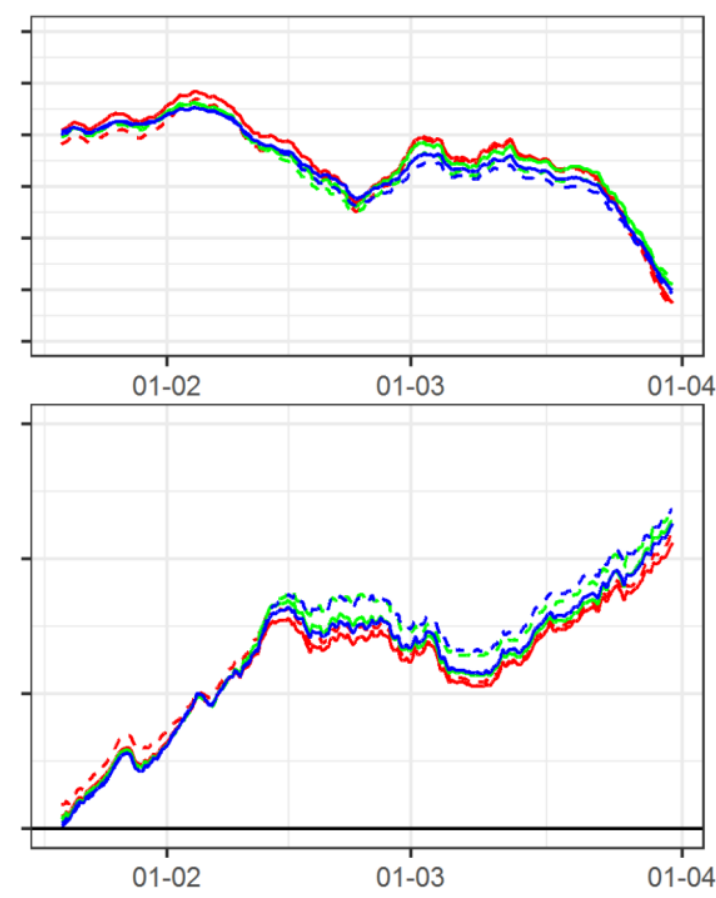

Insulation

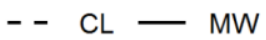

Fig. 6. Temperature and relative humidity in attics with different ventilation rates and ceiling constructions for January to March (Part 1). CL: cellulose-based insulation and MW: mineral-wool insulation. 
Without VB
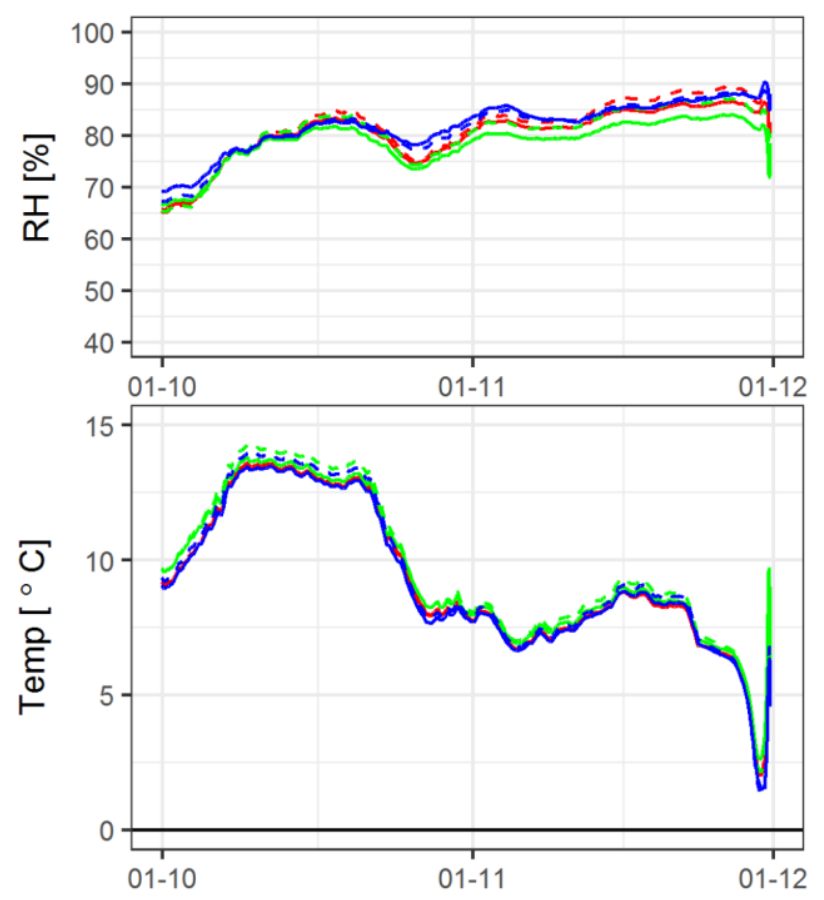

$\mathrm{ACH}$
With VB
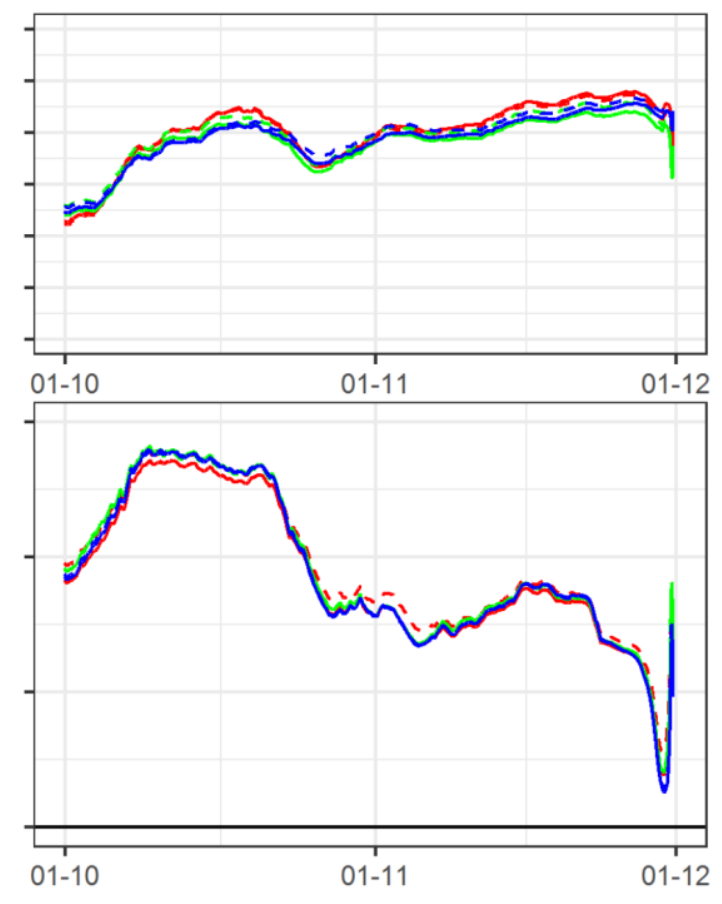

Insulation

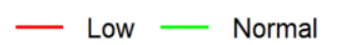

Very low

$-\mathrm{CL}-\mathrm{MW}$

Fig. 7. Temperature and relative humidity in attics with different ventilation rates and ceiling constructions for October and November (Part 2). CL: cellulose-based insulation and MW: mineral-wool insulation.

higher moisture content a higher risk of moisture related problems in the attic may occur; especially, if the ventilation rate in the attics is lower than recommended in the Danish guidelines. However, based on the findings in [1], the hygrothermal performance of the attic was not significantly affected by different humidity classes in the rooms below, however, it must be noted that the investigation only where for normal ventilation rates (ACH - Normal) in the attic.

It is especially noteworthy that the effect of a vapour barrier on the concentration of tracer gas from below seems to be highest with the highest ventilation rate, while the effect on the relative humidity is the opposite; here the effect of a vapour barrier seems to be highest when the ventilation rate is the lowest. The two phenomenon do support each other; with higher ventilation rate, more tracer gas and moisture can be removed. Although, the relative humidity was only slightly affected by the ventilation rate.

One reason why the effect of ventilation was minor than expected could be, that ventilation in clear nights may not remove moisture, on the contrary, humid air from the outside may meet a roof underside that is colder than the ambient air due to under cooling caused by radiation to the clear sky. Higher ventilation may therefore not always remove more moisture.

The presented measurements are averages of measurements from four sensors, see Figure 3. This could hide differences between measurements on North and South faced roof areas. However, the differences are small. Figure 8 shows the temperature of the four sensors, measured in the section with normal ventilation, no vapour barrier and cellulose-based insulation material are shown as an example. In this case, the temperature measured in the south are higher than in the north, however, this is not a general tendency. The influence of solar radiation does not seem to cause differences in the performance of the two sides of the roof. Having a roof underlay and ventilation between roof plates and the underlay may be an important factor. Presenting results with weekly running averages instead of hourly values has also reduced differences in peak values. This was done to make lines smoother and therefore easier to detect differences in temperature and humidity levels.

As described in $[1,2]$ the temperatures in the attics were not influenced by the thickness or type of insulation. Neither did the changed ventilation have any effect on the temperature.

Figure 9 shows the calculated MRD index for the period January to December and a guesstimate of the development of the MRD index. The calculation of the MRD index is based on hourly values of temperature and relative humidity, not weekly averages as shown in Figure 6 and 7. The used values are averages of four sensor measurements as shown in Figure 3. This means, these are not surface measurements, although this would have been more correct for the MRD index calculation. However, as temperatures measured by sensors attached to rafters were approximately the same as temperatures measured by sensors hanging in the air, the difference in 


\section{Cellulose - Without VB}

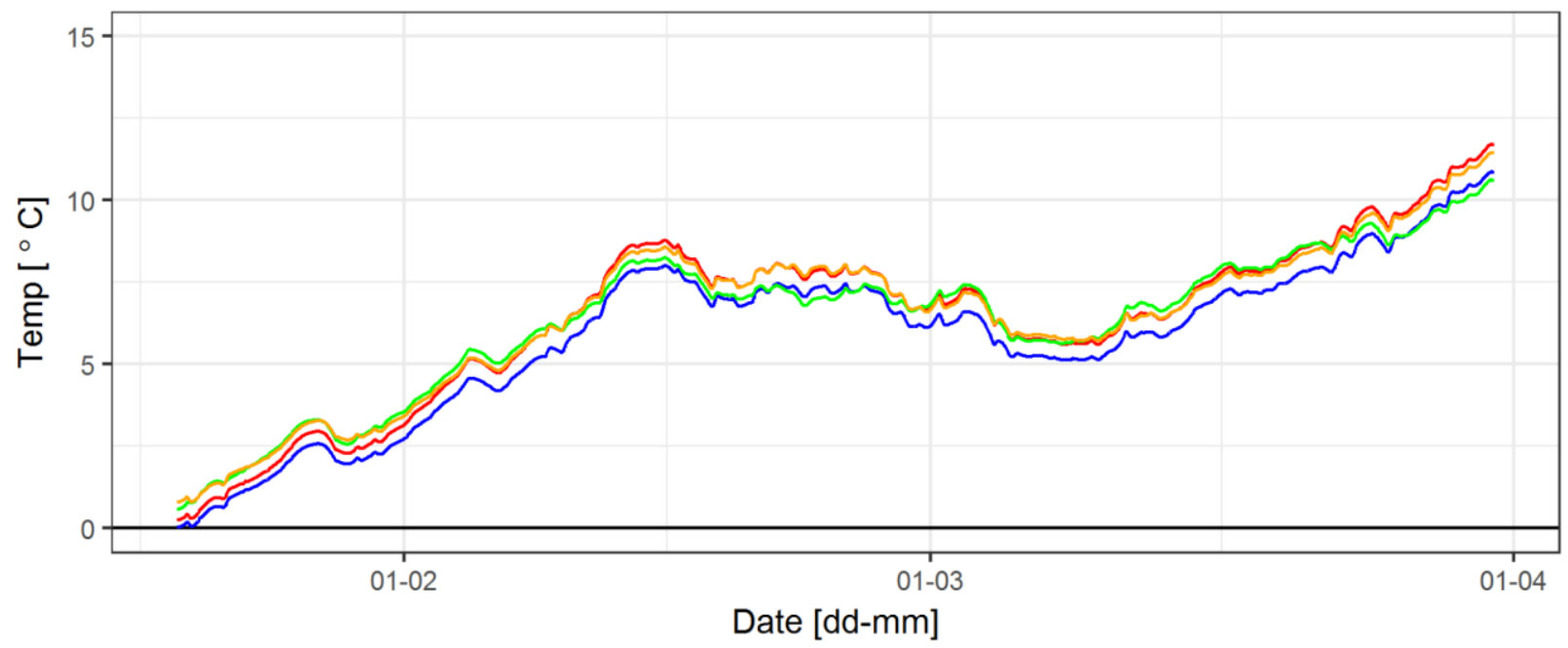

Sensorposition

Parameter

- Free - Ridge

Fig. 8. Example of the four temperature measuring points in the attic with $400 \mathrm{~mm}$ cellulose-based insulation without out vapour barrier and normal ventilation ( $\mathrm{ACH}-\mathrm{Normal})$.

surface conditions and ambient conditions were considered insignificant.

The winter season is typically the critical period for mould growth in attics, which is also shown on the MRD index and in Figure 6 and 7 where the relative humidity is below $70 \%$ in the end of April and beginning of October. Due to the lack of data, the presented mould growth risk in this paper shall be considered as indicative as no full-length period of a year is collected. Especially mould growth can slowly evolve, and measurements including a whole winter period could help determining whether the MRD index could exceed 1 before it would decline in the summer. The guesstimated MRD index will reach 1 around March and April, however this is with a linear development of the MRD curves. There is indications that the MRD index could reach 1 around April which correspond to the two measured periods in 2019 put together. However, this is not supported by the results, and the development in MRD index most likely do not follow a linear development. Furthermore, the increase in MRD index will probably cease and change into a decline in April where the relative humidity is below $70 \%$.

The MRD calculation presented in Figure 9 showed very low values of MRD indexes; nevertheless, there is an indication, that presence of vapour barrier is more important than ventilation rate when it comes to airtight ceiling constructions. Considering the new guidelines [4] on the possibility of omitting a vapour barrier in renovation projects, this study indicates that a reduced ventilation rate can be critical for attics moisture conditions and the risk of mould growth.

Furthermore, cellulose-based insulation material has a slightly higher MRD index than mineral wool. This is contrary to the expectations that there would be a moisture buffering effect in cellulose based material, and that this would be beneficial. Apparently, the retention of the curve for cellulose-based insulation material is lower than for mineral wool, meaning that when the conditions again become favourable for mould growth, the increase in MRD index starts from a higher point. This might be because of the hygroscopic properties; the material still contains moisture.

However, the value is very low and so are the differences, it will most likely have no practical implication, therefore neither the presence of a vapour barrier nor the hygroscopic properties are important if the ceiling is airtight, at least at the ventilation rates investigated in this paper. Of note, this study was conducted in two not connected winter periods - January to March and October to November. The first measured period was just after changing the ventilation conditions in the attics; hence, this can be the reason for not seeing fluctuation on the MRD index. If the period had been a contiguous period, the MRD index might have followed the guesstimated line in Figure 9 as the moisture buildup period would have been longer than starting in January, when the ventilation was changed.

\section{Conclusion}

This study investigates the importance of ventilation in attics, whether it is risky to reduce the ventilation in attics, something that can easily happen e.g. in connection with installation of additional insulation. The ventilation rates were reduced by $35 \%$ and $52 \%$, respectively. However, the relative humidity was only slightly influenced; and in cases without vapour barrier, 


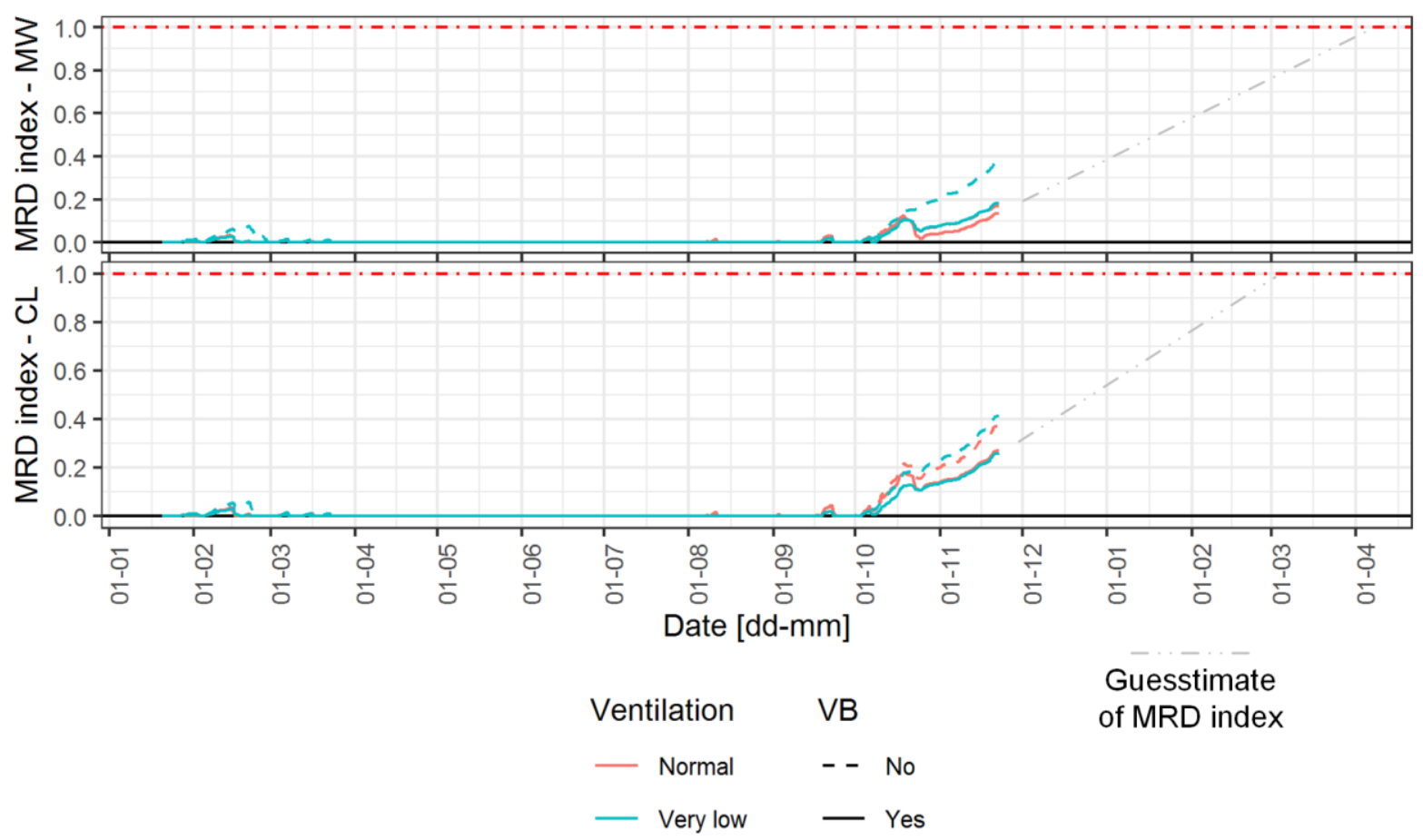

Fig. 9. MRD index calculated based on the measured temperature and relative humidity. Normally the threshold value is set at 1 (red dash-dot line). All results are much lower. If the MRD index is guesstimated with a linear development the MRD index is 1 around April and March. MW is mineral wool and CL is cellulose-based material.

the changes were a little larger than in cases with vapour barrier.

Calculations of the risk of initiation of mould growth support, that there is no risk as the maximum MRD index after two months (October and November) is 0.4 , where 1 would be acceptable. However, the results are from two half winters, a continuous winter may show more critical MRD levels.

Based on the findings, it is not recommend changing the Danish guidelines of ventilation rates in the attic. Even though there are, some tendency that a lower ventilation rate has a minor effect on the hygrothermal performance the measured period is to short. Thereby, more data is needed and supported e.g. by simulations with different outdoor climates.

The authors thanks Axel Bluhme and Mikael Weiling for conduction the adjustments in the test facilities and starting up the measurements during their Master in Building Physics education [9].

\section{References}

1. T. Hansen, E. Møller, T. Tvedebrink, J. Build. Phys. (online first 16 Dec. 2019)

2. T. Hansen, E, Møller, Build. and Environ., 165, (2019)

3. E. Brandt et al., Moisture in buildings [in Danish: Fugt $i$ bygninger] (Statens Byggeforskningsinstitut, AAU, 2nd Ed., 2013)
4. E. Brandt, T. Bunch-Nielsen, M. Morelli, SBi guideline 273 Roofs [in Danish: Tage] (Statens Byggeforskningsinstitut, AAU, 2019)

5. EN ISO 13788:2013

6. N. C. Bergsøe, Passive tracer gas method for ventilation assessment [in Danish: Passiv sporgasmetode til ventilationsundersøgelser]. (Statens Byggeforskningsinstitut, 1992)

7. S. Thelandersson, T. Isaksson, Build. and Environ., 65: 18-25, (2013)

8. S. Thelandersson, T. Isaksson, Moisture resistant design (MRD) model. [Online] Available at: https://wufi.de/de/wpcontent/uploads/sites/9/2016/04/Lund-MRDmodel.pdf (2016)

9. M. D. Weiling, A. Bluhme, Ventilations influence on hygrothermal conditions in ventilated roof space (in Danish: Ventilations influence on hygrothermal conditions in ventilated) Master thesis, Statens Byggeforskningsinstitut, AAU (2019) 